\title{
Natural Experiments that Allow to Study Potential Drugs in Coronavirus Disease 2019 (COVID-19) from the General Practice Level
}

\author{
Jose Luis Turabian* \\ Specialist in Family and Community Medicine, Health Center Santa Maria de Benquerencia, Regional \\ Health Service of Castilla la Mancha (SESCAM), Toledo, Spain
}

\begin{abstract}
It is proposed to take advantage of the "natural experiments" in the prescription of drugs that have been reported as potentially useful for the treatment of COVID-19. Many of these are used in their licensed indications for a wide variety of health problems. Thus, the exposure to these drugs and the results of the disease (duration of symptoms, severity, hospitalization, viral load, etc.) could be studied. Therefore, patients treated with: 1) Azithromycin and doxycline (for various infections); 2) Alpha1 antagonists (for hypertension or benign prostatic hypertrophy); 3) Tocilizumab (in the treatment of various types of arthritis; 4) Statins (for dyslipidemia); 5) Selective serotonin reuptake inhibitors (fluoxetine, citalopram, sertraline, paroxetine, fluvoxamine, etc.) for depression/anxiety; 6) Antipsychotics; 7) Progesterone; 8) Vitamin D or calcifediol (25OHD); 9) Vitamin C; 10) Colchicine (for rheumatological and cardiac conditions); 11) ACE inhibitors (ACE-I) and AT1-A; 12) Ivermectin (as treatment and control of various tropical diseases; 13) Beta-blockers such as propranolol, nebivolol, carvedilol, atenolol, etc. (for heart problems and high blood pressure); and 14) Antihistamines such as clemastine and cloperastine (for coughs of various causes), they could be tested immediately. These researches could have a retrospective character (of computerized medical records at the level of general medicine), to find patterns, trends and associations both in small and selected samples, as well as in large data sets.
\end{abstract}

\section{Keywords}

COVID-19, SARS-CoV-2, Biomedical Research, Coronavirus Infections/therapy, COVID-19 drug treatment, Comorbidity, General practice, Epidemiology

\section{Introduction}

Therapeutic options and vaccines for coronavirus disease 2019 are desperately needed to respond to severe acute respiratory syndrome coronavirus 2 (COVID-19) pandemic. However, there can be a long way to go to find an effective vaccine. Meanwhile, tools are needed to keep people alive, improve symptoms, and reduce the duration and severity of illness. It is in this context where it would be very useful to find an antiviral drug that acts early, so that transmission can be reduced and contribute to the control of outbreaks [1].

The drugs for which the first useful results are obtained refer to hospitalized and seriously ill patients. Thus, with respect to remdesivir, it is suggested that this drug shortens the course of the disease for hospitalized patients and reduces the risk of death by up to $62 \%$ in critically ill patients; so, viral infection develops less quickly and patients in severe state recover an average of four days earlier than usual $[2,3]$. And, dexamethasone, it reduced death rates by about a third among seriously ill hospitalized COVID-19 patients [4].

But, none of these interventions is applicable at the on- set of the disease or at the community level at the general medicine (GM) level. Therefore, it would be a good question to ask about outpatient treatment of mild-moderate disease. This is where research and publications are lacking. All there is "anecdotal" evidence; this line of investigation has been overlooked. It should be borne in mind that all severe and critical COVID-19 patients were previously mild or moderate COVID-19 patients or uninfected citizens.

Therefore, it is a good strategy to focus on early treatment research at the general practice level. Attention has been

*Corresponding author: Jose Luis Turabian, Specialist in Family and Community Medicine, Health Center Santa Maria de Benquerencia, Regional Health Service of Castilla la Mancha (SESCAM), Toledo, Spain

Accepted: November 07, 2020

Published online: November 09, 2020

Citation: Turabian JL (2020) Natural Experiments that Allow to Study Potential Drugs in Coronavirus Disease 2019 (COVID-19) from the General Practice Level. Arch Fam Med Gen Pract 5(1):123-129 
given to vaccines and inpatient therapeutics. But if you're spending \$20 billion on potential vaccines and billions more on diagnostics, we must allocate resources commensurate to drugs that could actually work, when given early, to prevent serious illness and death. Early treatment, if successful, would allow us to avoid the serious complications seen in COVID-19. So, these treatments given early could improve outcomes and prevent catastrophic complications in patients with COVID-19. But also, early treatment with an existing drug would be the fastest, most clinical, and most cost-effective way to mitigate the impact of COVID-19. That means reducing hospitalizations, which can reduce mortality, but it can also mean reducing viral load and that can have a profound impact on transmission within communities [1].

A number of drugs have been reported to be promising compounds for clinical trials against COVID-19: Some Medications can fight COVID-19 while others promote infectivity. These include: Camostat, a transmembrane serine protease inhibitor (TMPRSS2) licensed for use in Japan to treat pancreatitis and esophagitis, combined with the antiandrogen bicalutamide, zotatifine and ternatine-4/plitidepsin), niclosamide, doxazosin, favipiravir, leronlimab, interferon beta, interferon lambda, and other monoclonal antibodies $[1,5,6]$.

On the other hand, a number of drugs modulate proteins within the cell known as Sig-1R and Sigma2, promising for clinical trials against COVID-19, including fluvoxamine, a commonly prescribed drug for depression, and which is a regulator of serotonin, but also activates the sigma-1 receptor, progesterone, PB28, PD-144418, hydroxychloroquine, the antipsychotic drugs haloperidol and cloperazine, siramesin, an antidepressant and anxiolytic drug, and the antihistamines clemastine and cloperastine $[5,6]$.

Existing drugs could play a role in mitigating COVID-19 or slowing its transmission. The two promising categories of drugs focused on COVID-19 viral infection and immunopathology are classic antiviral (or repurposed drugs with antiviral activity) and immunomodulators. Drug repurposing is a particularly interesting and fast path within the reach of clinical drugs. Drug manufacturers do not test their drugs for all the diseases for which they might be effective. So, drug repurposing can work. The advantage of a repurposed drug is that research on its effect is much faster and easier. These data would help prioritize the drugs to be tested in larger confirmatory studies [1].

It must be taken into account that the strategies to develop a new therapy will require a lot of time and very extensive resources. Therefore, drug reuse has become an ideal strategy towards a smart, versatile and rapid way of possible COVID-19 treatments $[7,8]$. Thus, drugs whose operation has already been tested in people -even against other viruses or in other indications- are the ones that are most likely to be used in the short term [2].

Although it is somewhat clear that these circumstances may shed light on the effects of drugs on COVID-19, to date studies are not generalizing, and even less from general medicine. In this scenario, this article aims, to reflect and systematize on the suggestion of taking advantage of the "natural experiments" that exist, of the use of potential drugs for the treatment of COVID-19, already existing and prescribed in its authorized indications, in patients with other diseases in addition to COVID-19, or for symptoms present in COVID-19, administered early and at the level of general or out-of-hospital medicine, to assess its usefulness in the results such as reduction of the duration of symptoms, reduction in severity, catastrophic complications, hospitalizations, mortality, viral load, among other endpoints, as well as assessing their impact on transmission within communities.

\section{Methods}

For the literature review, a pragmatic approach was used that was based on a non-systematic or opportunistic search for information, considering the bibliographic references of selected articles, reviews of books related to the topic and searches on the Internet based on published studies on COVID-19 treatment. The comments in this article should be considered as a personal point of view, based on the author's experience and the review cited above.

\section{Discussion}

The investigation of therapies against COVID-19 accumulates failures. The only two acceptable drugs so far remdesivir and dexamethasone. However, other options are possible. Using artificial intelligence and other methods, all known drugs have been mapped against all the possible mechanisms in which the severe acute respiratory syndrome coronavirus 2 (SARS-CoV-2) operates to cause complications [1,5,6,9]. In this way, an extensive list of existing drugs has been reported that could have a potentially useful role for the treatment of COVID-19. Some of them have already been studied in some depth and many others are being studied or clinical trials are being designed.

It is true that, so far, the impact of drug treatments in the COVID-19 pandemic remains limited [10]. It can be said as of this writing that the only pharmacological interventions with proven benefit in this early stage of the pandemic include the use of immunomodulatory therapies in patients with severe respiratory problems (ventilated or oxygen dependent): remdesivir and dexamethasone $[11,12]$. And, on the other hand, the uses of these drugs refer to hospitalized and seriously ill patients [2-4]. In addition, other drugs or treatments initially used, in which great hopes were placed, have failed, such as hydroxychloroquine [13-16], or the convalescent plasma therapy $[17,18]$.

\section{Potentially useful drugs for COVID-19 that are routinely prescribed as authorized treatment for certain diseases or symptoms}

There are drugs, potentially useful for COVID-19, which are prescribed regularly in some places and in a more or less intense way, as authorized treatment of certain diseases or symptoms. In this way, inadvertently "natural experiments" are being carried out, which go unnoticed, in places where these drugs are used in their authorized indications during COVID-19 outbreaks. These "natural experiments" would allow, through common sense, clinical observation and the 
Citation: Turabian JL (2020) Natural Experiments that Allow to Study Potential Drugs in Coronavirus Disease 2019 (COVID-19) from the General Practice Level. Arch Fam Med Gen Pract 5(1):123-129

Table 1: Potentially useful drugs for the early treatment of COVID-19 in general medicine and which are being prescribed in their authorized indications during the outbreak of COVID-19

\begin{tabular}{|c|c|c|c|c|}
\hline $\begin{array}{l}\text { Potentially useful } \\
\text { drugs for COVID-19 }\end{array}$ & $\begin{array}{l}\text { Illnesses or symptoms for } \\
\text { which drugs potentially } \\
\text { useful for COVID-19 are } \\
\text { currently prescribed }\end{array}$ & $\begin{array}{l}\text { Estimate of prevalence of } \\
\text { diseases in general medicine } \\
\text { office for which drugs } \\
\text { potentially useful for COVID-19 } \\
\text { are being prescribed }\end{array}$ & $\begin{array}{l}\text { Estimated number of } \\
\text { patients with health } \\
\text { problems in a general } \\
\text { medicine office with a list } \\
\text { of } 2,000 \text { patients }\end{array}$ & $\begin{array}{l}\text { Ease of conducting } \\
\text { retrospective studies } \\
\text { of drug exposure and } \\
\text { COVID-19 results in } \\
\text { general medicine }\end{array}$ \\
\hline Azithromycin & Various bacterial infections & $5-10 \%$ & 100 & $\begin{array}{l}\text { Relatively frequent use. } \\
\text { Relatively wide sample }\end{array}$ \\
\hline Alpha1 antagonists & $\begin{array}{l}\text { Arterial hypertension, } \\
\text { benign prostatic } \\
\text { hypertrophy }\end{array}$ & $\begin{array}{l}20 \% \text { (hypertension) } \\
80 \% \text { of those over } 50 \text { years } \\
\text { (benign prostatic hypertrophy) }\end{array}$ & $\begin{array}{l}400 \text { (hypertension) } \\
80 \text { (benign prostatic } \\
\text { hypertrophy) }\end{array}$ & $\begin{array}{l}\text { Frequent use. Large } \\
\text { sample }\end{array}$ \\
\hline Tocilizumab & Various types of arthritis & $0.5 \%$ rheumatoid arthritis & 10 & $\begin{array}{l}\text { Infrequent use. Small } \\
\text { sample }\end{array}$ \\
\hline Statins & Dyslipidemia & $30-50 \%$ & 800 & $\begin{array}{l}\text { Very frequent use. Very } \\
\text { large sample }\end{array}$ \\
\hline $\begin{array}{l}\text { Selective serotonin } \\
\text { reuptake inhibitors }\end{array}$ & Depression / anxiety & $5-20 \%$ & 200 & $\begin{array}{l}\text { Very frequent use. Large } \\
\text { sample }\end{array}$ \\
\hline Antipsychotic & Psychosis & $1 \%$ & 20 & $\begin{array}{l}\text { Infrequent use. Small } \\
\text { sample }\end{array}$ \\
\hline Progesterone & $\begin{array}{l}\text { Different obstetric } \\
\text { gynecological conditions }\end{array}$ & $20 \%$ of women & 200 & $\begin{array}{l}\text { Infrequent use. Small } \\
\text { sample }\end{array}$ \\
\hline $\begin{array}{l}\text { Vitamin D or } \\
\text { calcifediol ( } 25 \mathrm{OHD})\end{array}$ & $\begin{array}{l}\text { Risk factor for various } \\
\text { chronic diseases }\end{array}$ & $50 \%$ & 1000 & $\begin{array}{l}\text { Relatively frequent use. } \\
\text { Moderately large sample }\end{array}$ \\
\hline Vitamin C & Malnutrition & $\begin{array}{l}12 \% \text { in elderly, indigent, } \\
\text { alcoholic and malnourished }\end{array}$ & 10 & $\begin{array}{l}\text { Very infrequent use. Very } \\
\text { small sample }\end{array}$ \\
\hline Colchicine & $\begin{array}{l}\text { Rheumatological and } \\
\text { cardiac conditions }\end{array}$ & $\begin{array}{l}5-7 \% \text { of patients with } \\
\text { hyperuricemia }\end{array}$ & 100 & $\begin{array}{l}\text { Infrequent use. Small } \\
\text { sample }\end{array}$ \\
\hline $\begin{array}{l}\text { ACE inhibitors } \\
\text { and AT1 receptor } \\
\text { antagonists }\end{array}$ & Hypertension, heart failure & $\begin{array}{l}20 \text { hypertension; } 10 \% \text { of heart } \\
\text { failure in those over } 70 \text { years }\end{array}$ & $\begin{array}{l}400 \text { (hypertension); } \\
10 \text { heart failure }\end{array}$ & $\begin{array}{l}\text { Frequent use. Large } \\
\text { sample }\end{array}$ \\
\hline Ivermectine & Several tropical diseases & - & - & Use in tropical areas only \\
\hline Beta-blockers & $\begin{array}{l}\text { Heart problems and high } \\
\text { blood pressure }\end{array}$ & Up to $20 \%$ & 200 & $\begin{array}{l}\text { Relatively frequent use. } \\
\text { Relatively large sample }\end{array}$ \\
\hline Antihistamines & $\begin{array}{l}\text { Allergies, cough of various } \\
\text { causes }\end{array}$ & $20 \%$ allergies; $9 \%$ to $33 \%$ cough & 400 allergies; 200 cough & $\begin{array}{l}\text { Frequent use. Large } \\
\text { sample }\end{array}$ \\
\hline
\end{tabular}

performance of retrospective cases-control studies, provide valuable information before deciding to conduct clinical trials $[19,20]$. These potentially useful drugs in the treatment of COVID-19 are showed in Table 1. These would be:

1. The antibiotics azithromycin (AZM) -a macrolide antibiotic-, and doxyclyne -an antibiotic from the group of tetracyclines [21]. AZM is an antibiotic that tends to be empirically prescribed in COVID-19. It has been the subject of some experimental treatments for coronavirus patients [22] (as well as for severe respiratory syncytial virus infection in young children as it could reduce hospital stay and endotracheal markers for viral replication) [23]. AZM is a classic antibiotic in the treatment of respiratory infections of bacterial origin. But its use in COVID-19 is being analyzed due to the high risk of associated bacterial infections and the anti-inflammatory effect of this antibiotic. AZM kills senescent cells; in addition, normal healthy cells thrive in the presence of AZM. The new interpretation is that the antibiotic is likely to kill "inflammatory" fibroblasts, which could be useful as a preventive treat- ment for older people, as well as a treatment for people who already have the virus $[24,25]$.

On the other hand, since AZM (and doxycycline) are commonly used antibiotics that inhibit viral replication because of functionally inhibits the synthesis of cellular proteins, could be useful for the treatment and prevention of COVID-19. In addition, AZM is an immune modulator that has been reported to provide clinical benefit in inflammatory airway diseases $[23,26]$.

2. Several alpha1 antagonists such as prazosin $[27,28]$ and doxazosin, used as a treatment for arterial hypertension (and doxazosin also for benign prostatic hypertrophy) prevent death from cytokine storm in animal models [29,30].

3. Ribavirin, that has antiviral activity against COVID-19 in vitro and improved the strategies developed during the prior SARS and MERS outbreaks [31].

4. Tocilizumab, which is a recombinant humanized mono- 
clonal antibody that acts as an interleukin 6 receptor inhibitor and is approved to treat various types of arthritis. Tocilizumab is being tested in patients with severe COVID-19 and elevated interleukin- 6 because interleukin- 6 appears to be involved in the cytokine storms [32-34].

5. Interferon $\alpha$ and $\beta$. Its use is highly controversial. Both substances are associated with serious side effects. Although its administration in the early stages of the disease is associated with the expected positive effect, a late administration can intensify the cytokine storm, causing inflammation and, consequently, worsening the patient's condition [35].

6. Statins have common effects including regulation of cytokine storm and inflammation and inhibition of autophagy flow. Statins are lipid-lowering drugs with pleiotropic effects. They have shown benefits in the management of inflammatory and autoimmune diseases such as systemic lupus erythematosus, rheumatoid arthritis, and multiple sclerosis. Furthermore, due to their immunomodulatory properties, they have been used in the treatment of various infectious diseases such as community-acquired pneumonia and influenza [35-37].

7. Fluvoxamine, an antidepressant that can prevent overreactions of the immune system (cytokine storms) [38]. In fact, all drugs that facilitate serotonin transmission can also attenuate the cytokine storm associated with COVID-19 (fluoxetine, citalopram, sertraline, paroxetine, fluvoxamine, etc.) [28].

8. The antipsychotic drugs haloperidol and chlorpromazine (CPZ). The latter is a phenothiazine derivative widely used in clinical routine in the treatment of acute and chronic psychoses. In addition to its antipsychotic effects, several in vitro studies have also demonstrated antiviral activity of CPZ through inhibition of clathrin-mediated endocytosis [39].

9. The hormone progesterone. The risk of severe COVID-19 outcomes is consistently lower in women than men worldwide, suggesting that female biological sex is critical for protection. Sex hormones play an important role in the immune response, with estrogen seen as an immune booster (progesterone has anti-inflammatory properties) and testosterone as an immunosuppressant. Furthermore, an important protease involved in viral entry, TMPRSS2, is regulated by progesterone $[40,41]$.

10. Vitamin D. Vitamin D receptor activation act on many cellular and biochemical mechanisms responsible for Acute Respiratory Distress Syndrome. Vitamin D supplementation, either as vitamin $\mathrm{D}$ or calcifediol (25OHD), is being tested in several randomized controlled trial as to demonstrate its potential effects on the course of COVID-19 [42,43].

11. Vitamin C. High-dose intravenous vitamin C (ascorbic acid) is an antioxidant and reducing agent. It has been investigated in the treatment of sepsis because of its enhancement of the immune response. In the intensive care setting, vitamin $\mathrm{C}$ administration has been correlated with preventing progressive organ dysfunction and reducing mortality in sepsis and acute respiratory distress syndrome and is being investigated in critically ill patients with COVID-19 [44,45].
12. Colchicine is a plant-derived alkaloid with anti-inflammatory properties that is used for a variety of rheumatological and cardiac conditions. It is hypothesized that colchicine could treat COVID-19 through targeting the overactive interleukin-6 pathway $[44,46,47]$.

13. Angiotensin-converting enzyme (ACE) inhibitors are the basis for the treatment of heart failure with impaired left ventricular systolic function (ejection fraction $<40 \%$ ) of classes II-IV according to the New York Heart Association. An alternative to ACE inhibitors, mainly used in the case of side effects associated with inhibition of bradykinin degradation, including persistent dry cough, are angiotensin II type 1 (AT1) receptor antagonists. Both groups belong to the most basic drugs used in the treatment of hypertension, which makes them two of the most commonly used medications in the world, especially in the elderly population. It has been hypothesized that binding of the virus to Angiotensin-converting enzyme 2 during the development of pneumonia disrupts homeostasis by violating the Renin-Angiotensin-Aldosterone system, further aggravating the patient's condition. Therefore, when used in patients who develop fully COVID-19, ACE inhibitors and AT1 receptor antagonists can reduce symptoms and even reduce mortality $[35,48]$.

14. Ivermectine. It is a broad spectrum antiparasitic drug used for the treatment and control of several neglected tropical diseases. It inhibits the in vitro replication of some positive single-stranded RNA viruses, such as dengue virus, Zika virus, yellow fever virus, and others. Ivermectin has been reported to be a potent inhibitor of the in vitro replication of SARSCoV-2 $[35,49,50]$.

15. Various beta-blockers like propranolol, nebivolol, carvedilol, atenolol, etc. It has been suggested that the cytokine storm can be counteracted by a variety of clinically used drugs that reduce norepinephrine transmission (but may not act through direct effects on viral replication or viral entry into cells) [28].

16. Fenofibrate which has a mode of action that reduces lipid accumulation in lung tissue and could improve COVID-19 outcome [51].

17. The antifibrinolytic agent aprotinin. In several studies it was shown that Aprotinin efficiently inhibits SARS-CoV-2 replication in vitro. Aprotinin is a nonspecific inhibitor of protease, especially trypsin, chymotrypsin, plasmin, and kallikrein, and has been in clinical use for many years. Aprotinin inhibits the release of pro-inflammatory cytokines and participates in the process of glycoprotein homeostasis. Experimental data support that the use of aprotinin to inhibit matrix metalloproteinases and the quinine-kallikrein system may be a potential new approach for the treatment of acute lung injury/Acute Respiratory Distress Syndrome [52].

18. And the antihistamines clemastine and cloperastine. Cloperastine is a widely used drug in the treatment of acute and chronic cough [53]. Cloperastine acts on the Sigma-1 receptor, an endoplasmic reticulum protein that mediate the signalling of a variety of drugs, and it is suggested that they modulate cytokines [54]. 


\section{Routine use of potentially useful drugs in the treatment of COVID-19}

The drugs described above are widely used in their licensed indications in many places. In this way, hundreds of "natural experiments" are being produced that could be used to assess, mainly retrospectively, the relationship of these existing drugs applied early in the course of the disease, with results of COVID-19, such as duration of symptoms, severity of the disease, hospitalization, viral load, etc., at the level of general medicine or out-of-hospital.

It would not be a question of prescribing these drugs in an unapproved indication (COVID-19) to prove their efficacy, but rather to retrospectively evaluate those cases of COVID-19 that were exposed to these drugs, used in their approved indications, such as hypertension, depression, dyslipidemia or cough, etc.

Thus, in many places 4 facts converge that imply the existence of these "natural experiments" on the effect of potentially useful drugs for COVID-19:

1. The fact that these drugs are frequently prescribed and used in their authorized indications.

2. The fact that many of these places have presented or are presenting high rates of infection and mortality by COVID-19.

3. That at the level of general medicine, there are computerized records of the medical records of the patients, where the prescribed drugs, presence of COVID-19, and results or different endpoints (such as duration of symptoms, hospitalization, severity, medical complications, viral load, death, etc)., and all these data can be extracted.

4. That the frequency or prevalence of the diseases for which these drugs are prescribed is, on many occasions, high. So, according to prevalence data normally accepted there is $20 \%$ of hypertensive patients, between $5-20 \%$ of cases of depression, between $5-7 \%$ of patients with hyperuricemia, between $30-50 \%$ of dyslipidemia, etc. [55] (Table 1). These figures make it possible to obtain samples of adequate size to test results of previous drug exposure, even at the level of one medical office.

The coincidence of these 4 facts means an opportunity for common sense and clinical observation, offered by these natural experiments. This could be done easily, and with better epidemiological results, using computerized medical records and big data analysis techniques. These analyses of large data sets will find patterns, trends and associations [56].

Thus, patients, treated with AZM, doxyclyne (for various infections), with alpha1 antagonists (for example for arterial hypertension or benign prostatic hypertrophy), with tocilizumab (in the treatment of various types of arthritis, with statins (for dyslipidaemia), with selective serotonin reuptake inhibitors (fluoxetine, citalopram, sertraline, paroxetine, fluvoxamine, etc.) for depression/anxiety, with antipsychotics, with progesterone, with vitamin D or calcifediol (25OHD), with Vitamin C, with colchicine (for rheumatological and car- diac conditions), with ACE inhibitors (ACE-I) and AT1-A, with ivermectine (as treatment and control of various tropical diseases), with beta-blockers such as propranolol, nebivolol, carvedilol, atenolol, etc. (for heart problems and hypertension arterial), and with antihistamines such as clemastine and cloperastine (for cough of different causes), can be immediately examined through a retrospective epidemiological investigation of the medical records [28] (Table 1).

The study hypothesis presented here is that patients with these treatments for various approved indications (diseases or symptoms) (such as hypertension, benign prostatic hypertrophy, heart failure, dyslipidaemia, psychiatric, allergies, coughs, rheumatological diseases, etc.) could have been protected from severe forms of COVID-19, or they could improved various endpoints of COVID-19 management, through exposure to these drugs [39].

Despite these arguments, randomized clinical trials -and there are more than 1000 clinical trials that analyze a variety of pharmacological treatments [4] continue to be the best method available to understand the causal relationship between an intervention and subsequent evolution at population level for most diseases. But, in the absence of data from randomized clinical trials, researchers are obliged to rely on common sense supplemented by personal clinical experience and the retrospective studies [19].

\section{Conclusions}

It is proposed to use, immediately, at the level of general medicine, especially from computerized medical records, and large databases, the fact that there are thousands of "natural experiments" of exposure to drugs potentially useful for treatment in early stages of COVID-19, which are being prescribed for their authorized indications. These studies would allow epidemiological assessment of its effects on various COVID-19 endpoints. Also, the results could guide which drugs should be evaluated in clinical trials.

\section{References}

1. Stokowski L (2020) Could these old drugs help fight COVID and save lives? Medscape.

2. (2020) NIH clinical trial shows Remdesivir accelerates recovery from advanced COVID-19. NIH.

3. Spinner CD, Gottlieb RL, Criner GJ, et al. (2020) Effect of Remdesivir vs standard care on clinical status at 11 days in patients with moderate COVID-19: A randomized clinical trial. JAMA 324: 1048-1057.

4. Scudder L (2020) Drug treatment for COVID-19: A quick summary for PCPs. Medscape.

5. Gordon DE, Jang GM, Bouhaddou M, et al. (2020) A SARS-CoV-2 protein interaction map reveals targets for drug repurposing. Nature 583: 459-468.

6. (2020) Revealing how SARS-CoV-2 hijacks human cells; points to drugs with potential to fight COVID-19 and a drug that aids its infectious growth. Institut Pasteur.

7. Nazeam J, Mohammed EZ, Raafat M, et al. (2020) Based on principles and insights of COVID-19 epidemiology, genome sequencing, and pathogenesis: Retrospective analysis of Sinigrin 
Citation: Turabian JL (2020) Natural Experiments that Allow to Study Potential Drugs in Coronavirus Disease 2019 (COVID-19) from the General Practice Level. Arch Fam Med Gen Pract 5(1):123-129

and Prolixin ${ }^{\mathrm{RX}}$ (Fluphenazine) provides off-label drug candidates. SLAS DISCOVERY.

8. Zimmer C (2020) Old drugs may find a new purpose: Fighting the coronavirus. The New York Times.

9. Brooks M (2020) Six potential treatments for COVID-19 identified. Medscape.

10. Editorial (2020) Curing COVID-19. Lancet Infect Dis.

11. Beigel JH, Tomashek KM, Dodd LE, et al. (2020) Remdesivir for the treatment of Covid-19. N Engl J Med.

12. Recovery Collaborative Group (2020) Effect of dexamethasone in hospitalized patients with COVID-19 Preliminary Report. N Engl J Med.

13. Skipper CP, Pastick KA, Engen NW, et al. (2020) Hydroxychloroquine in nonhospitalized adults with early COVID-19: A randomized trial. Ann Intern Med.

14. Schluger NW (2020) The saga of hydroxychloroquine and COVID-19: A cautionary tale. Ann Intern Med.

15. Nebehay S (2020) WHO halts hydroxychloroquine, HIV drugs in COVID trials after failure to reduce death. Medscape.

16. Nguyen LS, Dolladille C, Drici MD, et al. (2020) Cardiovascular toxicities associated with hydroxychloroquine and azithromycin: An analysis of the World Health Organization pharmacovigilance database. Circulation.

17. Dasgupta A (2020) Indian study shows no survival benefit of plasma in COVID-19. The Scientist.

18. Agarwal A, Mukherjee A, Kumar G, et al. (2020) Convalescent plasma in the management of moderate COVID-19 in India: An open-label parallel-arm phase II multicentre randomized controlled trial (PLACID Trial). MedRxiv.

19. Bahit C (2020) Randomized clinical trials versus common sense and clinical observation. Medscape.

20. Turabian JL (2020) A case control-study of cloperastine treatment in COVID-19. Potential drug, clinical observation and common sense. Epidemol Int J. In Press.

21. Turabian JL (2020) Acute respiratory infections in children during coronavirus disease 2019: Without reverse transcriptase-polymerase chain reaction test and with risk of over-prescription of antibiotics, the perfect storm. Pediatric Infect Dis 5: 1.

22. Davis M (2020) 'It's scary for children': Mom discusses 3-yearold's COVID-19 diagnosis, experimental treatment. Asbury Park Press. USA Today.

23. Kong M, Zhang WW, Sewell K, et al. (2020) Azithromycin treatment vs placebo in children with respiratory syncytial virus-induced respiratory failure: A phase 2 randomized clinical trial. JAMA Netw Open 3: e203482.

24. University of Salford (2018) Antibiotics eliminate senescent cells associated with ageing. Medical Xpress.

25. Ozsvari B, Nuttall JR, Sotgia F, et al. (2018) Azithromycin and Roxithromycin define a new family of "senolytic" drugs that target senescent human fibroblasts. Aging (Albany NY) 10: 3294-3307.

26. Sargiacomo C, Sotgia F, Lisanti MP (2020) COVID-19 and chronological aging: Senolytics and other anti-aging drugs for the treatment or prevention of corona virus infection? Aging (Albany NY) 12: 6511-6517.

27. Konig MF, Powell M, Staedtke V, et al. (2020) Preventing cy- tokine storm syndrome in COVID-19 using $\alpha$-1 adrenergic receptor antagonists. J Clin Invest 130: 3345-3347.

28. Fitzgerald PJ (2020) Noradrenergic and serotonergic drugs may have opposing effects on COVID-19 cytokine storm and associated psychological effects. Med Hypotheses 144: 109985.

29. (2020) COVID-19 evidence accelerator collaborative lab meeting \#6.

30. Koenecke A, Powell M, Xiong R, et al (2020) Alpha-1 adrenergic receptor antagonists to prevent hyperinflammation and death from lower respiratory tract infection.

31. Khalili JS, Zhu H, Mak NSA, et al. (2020) Novel coronavirus treatment with ribavirin: Groundwork for an evaluation concerning COVID-19. J Med Virol.

32. Sheppard M, Laskou F, Stapleton PP, et al. (2017) Tocilizumab (actemra). Hum Vaccin Immunother 13: 1972-1988.

33. Manufacterer's Packge Insert (2020) Actemra (tocilizumab).

34. Luo P, Liu Y, Qiu L, et al. (2020) Tocilizumab treatment in COVID-19: a single center experience. J Med Virol 92: 814-818.

35. Drożdżal S, Rosik J, Lechowicz K, et al. (2020) FDA approved drugs with pharmacotherapeutic potential for SARS-CoV-2 (COVID-19) therapy. Drug Resist Updat 53: 100719.

36. Lima Martínez MM, Contreras MA, Marín W, et al. (2020) Statins in COVID-19: is there any foundation? Clin Investig Arterioscler.

37. Yeager A (2020) Could statins reduce the severity of COVID-19? The Scientist.

38. Clinical Trials (2020) US researchers evaluate antidepressant fluvoxamine for Covid-19.

39. Plaze M, Attali D, Petit AC, et al. (2020) Repositionnement de la chlorpromazine dans le traitement du COVID-19: étude reCoVery/Repurposing of chlorpromazine in COVID-19 treatment: The reCoVery study. L'Encéphale 46: S35-S39.

40. Franck Mauvais-Jarvis, Sabra L Klein, Ellis R Levin (2020) Estradiol, progesterone, immunomodulation, and COVID-19 outcomes. Endocrinology 161.

41. Strope JD, Chau CH, Figg WD (2020) Are sex discordant outcomes in COVID-19 related to sex hormones? Seminars in Oncology.

42. Quesada-Gomez JM, Entrenas-Castillo M, Bouillon K (2020) Vitamin $D$ receptor stimulation to reduce acute respiratory distress syndrome (ARDS) in patients with coronavirus SARS-CoV-2 infections: Revised Ms SBMB 2020_166. J Steroid Biochem Mol Biol 202.

43. Broyd N (2020) NICE: 'No evidence' to support vitamin D for COVID-19. Medscape.

44. Bilbul M, Paparone P, Kim AM, et al. (2020) Psychopharmacology of COVID-19. Psychosomatics 61: 411-427.

45. Baladia E, Pizarro AB, Ortiz-Muñoz L, et al. (2020) Vitamin C for COVID-19: A living systematic review. Medwave 20: e7978.

46. Deftereos SG, Giannopoulos G, Vrachatis DA, et al. (2020) Effect of colchicine vs standard care on cardiac and inflammatory biomarkers and clinical outcomes in patients hospitalized with coronavirus disease 2019: The GRECCO-19 randomized clinical trial. JAMA Netw Open 3: e2013136.

47. Rabbani AB, Parikh RV, Rafique AM (2020) Colchicine for the treatment of myocardial injury in patients with coronavirus disease 2019 (COVID-19)-an old drug with new life? JAMA Netw Open 3: e2013556. 
48. Hajra A, Bandyopadhyay D (2020) COVID-19 and ACEI/ARB: Not associated? Am J Hypertens 33: 788.

49. Offord C (2020) Surgisphere sows confusion about another unproven COVID-19 drug. The Scientist.

50. Chaccour C, Hammann F, Ramón-García S, et al. (2020) Ivermectin and COVID-19: Keeping rigor in times of urgency. Am J Trop Med Hyg 102: 1156-1157.

51. Whyte J, Nahmias Y (2020) Can cholesterol drugs and antihistamines fight COVID-19? Medscape.

52. Solun B, Shoenfeld $Y(2020)$ Inhibition of metalloproteinases in therapy for severe lung injury due to COVID-19. Med Drug Discov 7: 100052.
53. Catania MA, Cuzzocrea S (2011) Pharmacological and clinical overview of cloperastine in treatment of cough. Ther Clin Risk Manag 7: 83-92.

54. Zhu LX, Sharma S, Gardner B, et al. (2003) IL-10 mediates sigma1 receptor-dependent suppression of antitumor immunity. J Immunol 70: 3585-3591.

55. Peach H, Heller RF (1984) Epidemiology of common diseases. London. William heinemann Medical Books limited.

56. Wilfling D, Hinz A, Steinhäuser J (2020) Big data analysis techniques to address polypharmacy in patients - a scoping review. BMC Fam Pract; 21: 180.

DOI: $10.36959 / 577 / 493$

Copyright: (c) 2020 Turabian JL. This is an open-access article distributed under the terms of the Creative Commons Attribution License, which permits unrestricted use, distribution, and reproduction in any medium, provided the original author and source are credited. 